\title{
Un proyecto de Dios que defiende los intereses del imperio. Lectura crítica del libro de Nehemías desde los artífices opositores ${ }^{2}$
}

\author{
God's Project to defend the interests of the empire \\ Critical reading of the book of Nebemiah from the viewpoint of the opposing artifices
}

\begin{abstract}
Resumen
Nuestro ejercicio comienza por presentar una interpretación de la estructura literaria del libro de Nehemías, enfocándola desde la óptica de los opositores frente a la propuesta central del libro que favorece la incidencia del Imperio Persa, a través de Nehemías y Esdras, en Palestina en la época del retorno de los judíos a su tierra después del destierro babilónico. El análisis de esta estructura nos lleva a identificar aquellos textos que registran el grupo de los opositores y a otorgarle un reconocimiento crucial en la dialéctica interna de la obra de Nehemías. Este grupo es valorado como un movimiento que contribuye a generar conciencia en las clases populares en donde también participan profetas, profetizas, sacerdotes, mujeres y un sector del pueblo. El grupo de los opositores a la propuesta de reconstrucción de Jerusalén y de la nueva provincia persa se caracterizan como personas de gran influencia en la región y que tenían como propósito impulsar una reforma de nacionalismo
\end{abstract}

\begin{abstract}
Our exercise begins with a presentation of the literary structure of the book of Nebemiah, from the viewpoint of the opponents to the central proposal of the book that favored the incidence of the Persian Empire, through the eyes of Nehemiah and Ezra in Palestine in the period of the return of the Jews to their land following the Babylonian exile. The analysis of this structure leads us to identify the texts that describe the group of opponents and afford them crucial recognition in the internal dialectdic of the work of Nehemiah as a movement that contributes to generating awareness among the popular classes, with the additional participation of prophets, priests, women and a segment of the general population. The group of opponents to the proposal of rebuilding Jerusalem and a new Persian province is characterized as persons of great influence in the region whose aim was to promote an autonomous nationalist reform that would not have the political support of the Persians. The proposal, led by Tobias and his group, is described as offering special identity with its rise
\end{abstract}

Recibido el 28 de mayo de 2012 y aprobado el 9 de agosto de 2012.

1 Esteban Arias es Licenciado en filosofía y ciencias religiosas de la Universidad Santo Tomás. Licenciado en teología Seminario Teológico Presbiteriano Bogotá. Docente investigador del IBPL - Uniminuto.

2 Para la comprensión de la categoría artífice, en oposición a la categoría de sujeto, véase (Cañaveral, 2012, pp. 92-98). 
autónomo que no contara con el auspicio político de los persas. La propuesta liderada por Tobías y su grupo es identificada como una propuesta que guarda especial identidad con el auge que tuvo en el posexilio, una corriente de sabios y sabias de la cual participaban mujeres como la que presenta la novela de Ruth, las mujeres de Cantares y las del libro de los Proverbios. En ese grupo influyente de sabios y sabias confluía el profetismo popular al cual pertenecían profetisas como Noadías.

Palabras clave: Palestina, Imperio Persa, exilio babilónico, proyecto oficial, proyecto alternativo, Nehemías, artífices opositores(as), lectura popular de la Biblia, hermenéutica de la liberación. within the post-exile of a current of men and women sages and the participation of women, as shown in the novel of Ruth, the women of the Song of Songs and the book of Proverbs. That influential group of men and women sage was accompanied by the popular prophesy to which prophetesses like Noadia belonged.

Keywords: Palestine, Persian Empire, Babylonian exile, official project, alternative Project, Nehemiah, opposing artifices, popular reading of the Bible, bermeneutics of liberation. 


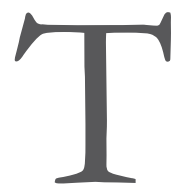

radicionalmente, estamos acostumbrados a leer la Biblia desde la óptica de quienes la escribieron. Ellos han presentado a los protagonistas como los grandes hombres o mujeres de Dios que debieran ser imitados en su acción por ser modelo de espiritualidad, honestidad, valentía o simplemente por ser enviados directamente por Dios a realizar misiones encomendadas en su nombre. Esto ha llevado a las iglesias a realizar lecturas fundamentalistas, cuyo resultado ha sido el afianzamiento de estructuras de poder injustas y excluyentes que no favorecen en nada el empoderamiento de grupos excluidos como mujeres, comunidades afro, indígenas, campesinos(as), etc. En el caso concreto del libro de Nehemías, hemos aprendido que existen unas personas que se oponen a la reconstrucción de Jerusalén en el posexilio y que resultan ser un obstáculo para el proyecto del pueblo de Dios, contraviniendo de manera deliberada sus propósitos.

Considero que tratar este tema es absolutamente apropiado en la coyuntura actual de Colombia pues los planes de reconstrucción del pueblo de Israel y sus instituciones, por parte del imperio persa durante el post-exilio, guardando las proporciones, se asemejan de manera importante a la incidencia de potencias como Estados Unidos, que interviene en la política nacional colombiana con ayuda militar para combatir la guerrilla y el narcotráfico, y recursos para la construcción de infraestructura vial con miras a favorecer un intercambio comercial ventajoso a través de acuerdos como el tratado de libre comercioTLC. A partir de la anterior intuición, ésta propuesta de trabajo sobre Nehemías genera dos preguntas que esperan ser respondidas en el trascurso del presente artículo: Primera, ¿qué relación puede existir entre quienes se oponen al proyecto de Nehemías y Esdras, y la propuesta que surge al interior del libro de Ruth como artífice de una sociedad alternativa? Segunda, ¿hasta qué punto el accionar de quienes se oponen al proyecto de Nehemías es auténtico y qué tendrían que ver, desde el punto de vista hermenéutico, con acciones similares a las de los grupos alternativos en Colombia, hoy en día, que luchan para que su voz sea escuchada y sus derechos reivindicados?

Para responder estas dos preguntas vamos a clarificar en una primera parte un esbozo general del contenido del libro; en un segundo momento identificaremos al interior de este contenido, cuáles son los textos donde tienen presencia los opositores de Nehemías, quiénes son esas personas y cuáles son sus proyectos; en tercer lugar, se discute cuál sería el vínculo entre el proyecto de estos opositores y la propuesta que parece en el libro de Ruth y finalmente, estableceremos la relación hermenéutica existente entre esta problemática registrada en el libro de Nehemías con el conflicto colombiano en nuestros días. 


\section{El contexto}

Israel cae bajo los babilonios en 597. En 538 Ciro, jefe guerrero y popular entre la tribu de los persas, conquista a Babilonia. Con la conquista de Babilonia se anexionó además Siria, Asiria y Palestina que estaban gobernadas por Nabónides, rey babilonio. En 529 muere Ciro y lo sucede Cambises, quien en el 525 anexionó al imperio a Egipto. Gaumata, un usurpador, sucede a Cambises pero este último es derrotado por Darío. Darío I, más conocido como Darío el Grande, consolidó el imperio creando una red de carreteras y un sistema de recaudación de impuestos. También expandió aún más el imperio, pero las guerras que mantuvo en las fronteras occidentales contra los griegos (499) no tuvieron el fruto esperado. Su hijo Jerjes I, que fue entronizado en el 486, tampoco logró ninguna victoria contra los griegos. En el 465 Jerjes y el príncipe heredero Darío mueren asesinados en un atentado, tras lo cual sube al poder Artajerjes I. Esta es la época en que Nehemías tramita su regreso a Judá para encargarse de la dirección de la reconstrucción de las murallas y el templo en Jerusalén, que habían sido destruidos por los babilonios. Ahora los persas se ponen sobre el control de Palestina y sus alrededores, a través de sus emisarios Esdras y Nehemías, lo cual genera resistencia entre los habitantes más influyentes de la región que querían recuperar el control. ${ }^{3}$

El capítulo 1 muestra que el único impulso de Nehemías fue la noticia del emisario de Artajerjes que había regresado de una visita oficial a Judá. Sin embargo, sabemos que algunos años después, en el 448, la revuelta de Megabises, uno de los gobernadores de
Palestina, modificó la situación en favor de Judá. Después de derrotar dos veces a los ejércitos del cuñado Artajerjes, Megabises obligó al rey a aceptar un acuerdo mediado por la reina Amestris, su hermana. El acuerdo, sin embargo, no debe haber dejado tranquilo al emperador, pues Megabises gozaba del apoyo y de la simpatía de los demás gobernadores de la región. Se tornó pues imperiosa la necesidad de tener aliados seguros en el área. El grupo judaíta, presente en la corte entre los cuales se encontraba Nehemías, debe haber presionado, a su vez, con el objetivo de recuperar los destinos de Judá. Esta es pues la coyuntura propia de la misión de Nehemías (Gallazzi, 1998, pp. 55-72).

\section{Un libro que se configura desde los intereses del Imperio Persa}

Los textos bíblicos, a mi juicio, tienen su origen en conflictos y problemáticas concretas en donde se vincula estructura literaria y realidad social. Norman Gottwald diría que: "el propio lenguaje como medio de literatura es un código social y, por tanto, la literatura es una expresión social" (1992, p. 23). Por eso en este apartado trataré de mostrar, a grandes rasgos, cómo el texto de Nehemías aunque no puede ocultar la presencia de los opositores, traza claramente su objetivo que consiste en descalificar a quienes se oponen a la reforma que impulsa el imperio persa para presentarla como adscrita al plan de Dios.

Estamos de acuerdo con los estudiosos de Nehemías ${ }^{4}$ en que el texto puede ser dividido en tres partes: (1) El retorno y la reconstrucción con apoyo del rey persa (capítulos 1-7);

3 Para ampliación de esta información véase Michaud (1995, pp. 15-60).

4 Véase Kilpp. (2005, pp. 131-141). Para la propuesta de estructura de Nehemías es importante anotar que este libro hace parte de la Obra Cronista que se configura como alternativa frente a la literatura sapiencial a la altura del año 300 a.C. Para la discusión de si originalmente Nehemías hacía parte de un solo libro junto a Esdras, véase el artículo del propio Nelson Kilpp. 
(2) La ley como sustento del proyecto imperial persa (capítulo 8-10); (3) La imposición del proyecto persa en Palestina, a pesar del esfuerzo de los opositores y su proyecto alternativo (capítulos 11-13).

En la primera parte, Nehemías es comisionado y viaja a Jerusalén (cap.1-2). Luego, Nehemías inicia la construcción de los muros de la ciudad, a pesar de la resistencia de los samaritanos y demás gobernadores de la región (cap. 3-4), realiza una reforma social producto de la protesta de las mujeres y demás gente del pueblo que se sentían ahora esclavizados en su propia tierra (cap. 5), concluye las murallas valiéndose de grupos de autodefensa (cap. 6) y repuebla la ciudad de Jerusalén (cap.7).

En la segunda parte (Nenemías 8-10), Esdras lee la Ley frente al pueblo y con este hecho se justifica la reedificación de Jerusalén que de alguna manera, está ocultando la pérdida de territorio y el control político imperial por parte de los persas (cap. 8), realiza una ceremonia de expiación, por causa de los matrimonios mixtos, que alerta contra el proyecto de los sabios y las sabias como el de Ruth, que incluye un credo histórico que recuerda la salida de Egipto, con lo cual sustenta una denuncia contra la esclavitud en su propia tierra que ya había sido denunciada en el capítulo 5 (cap. 9) y exige del pueblo el compromiso de cumplir las exigencias de la Ley (cap. 10).

En la tercera parte, la ciudad de Jerusalén es repoblada (11,1-3), la población fue inventariada en diversas listas, con resalte para el clero expresado a través de un género literario propio de los documentos de la corte $(11,4-12,26)$, se procedió a la dedicación de las murallas de Jerusalén (12,27-43) y se presentó un resumen de toda la época de Esdras y Nehemías $(12,44$-13,3), mencionándose todavía las realizaciones de la segunda misión de Nehemías que recupera, de hecho, el espacio ganado en su ausencia por sus enemigos que pretendían, a nuestro juicio, instaurar un orden nacionalista y orientado por la propuesta de las sabias de Jerusalén en la época del Cantar de los Cantares y libros como el de Ruth (13,4-31).

\section{Los opositores y su proyecto como alternativa}

\subsection{El registro de la oposición en los textos}

En el anterior apartado presentamos el contenido del libro de Nehemías a grandes rasgos. Hicimos también una especie de interpretación global de cada una de esas partes. Muchos temas saltan a la vista y otros quedan todavía sin explorar suficientemente. El tema de los opositores es apenas uno de los muchos asuntos que pueden ser tratados. Ese tema sólo aparece referido tres veces en el anterior ítem. Para intentar profundizar entonces en este tema vamos a presentar cada uno de los textos que plantean el asunto de los artífices opositores al proyecto persa en Nehemías. La primera mención que se hace de los enemigos es en Nehemías 2,10. Aquí, la manera como se califica la intensión de los opositores es tendenciosa: según los autores, a los opositores (Sambalat horonita y Tobías el siervo amonita) "les disgustó en extremo que viniese alguno para procurar el bien de los hijos de Israel" (Neh. 2,10b). Implícitamente, también se presenta la acción del imperio Persa a través de Nehemías como buena, sin observar las consecuencias futuras de este hecho. Luego, en 3,19 los opositores crecen en número pues a Sambalat y Tobías se une Gesem el árabe. Ahora la acusación de los autores contra los opositores se interpreta como "escarnio" y "desprecio" y de promulgar que la acción de reconstrucción era rebelión contra el rey, y esto era absurdo porque Nehemías contaba precisamente con el apoyo del rey persa.

El número de los opositores sigue creciendo y lo peor es que ahora ya se habla de conspiración. Ya no se trata solamente de tres de los líderes más influyentes de la región, sino 
que la rebelión adquiere carácter de movimiento, pues ahora se unen: "los árabes, los amonitas y los de Abdod" (Neh. 4,7).

Como si esto fuera poco, el movimiento de oposición alternativa adquiere ribetes, todavía más preocupantes para Nehemías y su gente cuando surge "gran clamor del pueblo y sus mujeres contra sus hermanos judíos" pues habían tenido que pedir "prestado grano para comer y vivir" y también habían tenido que empeñar sus tierras, sus viñas y sus casas "para comprar grano a causa del hambre", habían tenido que dar sus hijos e hijas en servidumbre ${ }^{5}$ sin posibilidad de rescatarlas porque sus tierras y sus viñas eran de otros (Neh. 5,1-5; 9,36s) ${ }^{6}$.

La situación de Nehemías se complica todavía más porque el movimiento trasciende a los profetas y a un sector del sacerdocio. Esto tiene un peso simbólico fundamental porque ya se trata de reñir contra elementos considerados sagrados pues, ¿qué es lo que hacen los profetas sino hablar en nombre de Dios y qué hace el sacerdocio sino sustentar en nombre de Dios las estructuras políticas de una sociedad determinada? Pues ahí estaban también en ese movimiento de oposición la profetiza Noadías y otros profetas (Neh. 6,14) y el sacerdote Eliasib, que le había otorgado un lugar en el templo a Tobías aprovechando que Nehemías había ido a entregar informe de su acción al rey persa (Neh. 13,4-14).

\section{2. ¿Quiénes eran los(as) opositores(as)? ${ }^{7}$}

El primero y más importante de los opositores de Nehemías es Tobías. Si bien por mucho tiempo se dudó de su nacionalidad judía, hoy nadie duda de este hecho por las siguientes razones: en primer lugar, está emparentado con los amonitas y esto lo vincula con la familia del grupo abrahámico, pues según Gn. 19, Amón es uno de los dos hijos de Lot junto a Moab. En segundo lugar es considerado un yavista auténtico pues su nombre es la abreviación de Yahveh y, en tercer lugar, son evidentes sus relaciones continuas con la clase sacerdotal (Neh 13,4-5) y con la aristocracia de Jerusalén (Neh 6,17-19). Además de estas razones de su vinculación judía, se añade su descendencia de la familia de Saúl (2 Samuel 9,1-13), de la familia de Jerson (1 de Cr 2,21-22) y su probado vínculo con los propios tobiadas posteriores. Su denominación como "siervo amonita" (Neh. 2,10), antes que un título despectivo, puede interpretarse, en el fondo, como un título de servicio a Yahveh y como una posición de jerarquía entre los persas y también entre los palestinos, cuya familia tenía grandes posesiones en Galaad aunque vivían en Jerusalén (Lockward, 2003, p. 1028). Como hemos dicho, los terrenos que la familia de los Tobíadas tenían en Trasjordania estaban antiguamente situados en la provincia de Galaad. Pero en la época persa el antiguo reino de Amón, con su capital en Rabbat-Amón, se anexionó a Galaad. El feudo de los Tobiadas, ampliado más todavía, se extendió por el territorio amonita para crear la Amanítida. Se piensa que el trasporte de las riquezas de oriente contribuyó a la prosperidad de la nueva provincia; la ruta comercial que unía la "Roca" con Damasco se hallaba a dos pasos de la fortaleza en que residía Tobías, el gobernador (Michaud, 1988).

Estos datos nos llevan a concluir que el personaje del que estamos hablando, no solamente era de una importancia capital en Transjordania, sino que habría que decir que al

5 Para el análisis de esta problemática económica en el contexto del libro de Nehemías véase Croatto (1990, pp. 27-37).

6 Esta situación es acorde con las denuncias del libro del profeta Isaías en su redacción pos-exílica. Para esta aproximación véase Croatto (1989, pp. 26-29).

7 Una alusión a algunos de estos personajes puede ser encontrada en Michaud (1988). 
vivir en Jerusalén y tener importantes contactos con el ala más consciente del sacerdocio y con un grupo importante de profetas y profetizas, su oposición a la reconstrucción emprendida por Nehemías llevaba consigo una propuesta implícita de nacionalismo y recuperación de la autonomía palestina alejada de la influencia política y explotación económica ejercida por el imperio de los persas.

Además de todo lo señalado sobre el principal personaje de la oposición al proyecto persa que encarnaban Esdras y Nehemías, hay que decir a su favor que no se encontraba sólo en su gesta. Contaba con un grupo de acompañantes, algunos de los cuales eran también de amplio reconocimiento e influencia en la región. El primero de ellos Sambalat. Este personaje, en el momento de la llegada de Nehemías a Jerusalén (445 a.C.), era el gobernador de Samaria, conformada en gran parte por algunos descendientes de los sobrevivientes de la invasión asiria en 722 y también por descendientes de los colonos asirios que vivían en la región después de esa invasión. Nehemías lo designa como "joronita" (Neh $2,10 ; 2,19 ; 13,28)$. ¿Hay que deducir de esto que procede de Bet-Joron localidad situada en las cercanías de Jerusalén? Según Michaud (1988), esto es posible, pero quizás se trate de un calificativo burlón. A pesar de su nombre babilonio, según este mismo autor, Sambalat pasa por ser un yavista de la misma camada de Tobias, su gran amigo. En favor de esta tesis se aduce que la forma abreviada de "Yahvé" aparece en la terminación de los nombres de sus dos hijos, Delaiah y Celemiah, citados en algunos documentos posteriores. Por otra parte, su hija se casó con el nieto de Eliasib, sumo sacerdote de Jerusalén (Neh 13,28). Los tratos del clero con los miembros sospechosos de Tobiyyah-Sambalat preocupan a Nehemías (Neh 13,29$)$ y esto reafirma todavía más nuestra tesis de que el movimiento de oposición se encontraba bien cimentado y amenazaba en convertirse en una propuesta con amplio apoyo de todos los sectores de la sociedad posexílica.
Completan el cuadro de opositores los asdoditas, en cuya capital Asdod se encontraba el gobernador de la región de filistea con presencia árabe, grupo vinculado con otro de los opositores de Nehemías el gran jeque árabe Gesen (Neh 2,19; 6,1). Según el propio Robert Micahud, una inscripción grabada en una vasija de plata descubierta en el sector oriental del Delta revela que aquella preciosa reliquia había sido ofrecida a la diosa Han-ilat por Quaynu, hijo de Gesen, rey de Cadar. Cadar, gran tribu nómada del desierto arábigo, está asociada a los nabateos, sus poderosos vecinos del nordeste. La vasija de plata que se encontró en el Delta del Nilo, a $800 \mathrm{Km}$ al oeste de Cadar, confirma lo que ya se ha sugerido: la presencia árabe está atestiguada en la región entre Gaza y Egipto. Además, la hegemonía árabe se ejerce también en las regiones situadas al sur de Judea: Idumea, el Negueb, el reino de Edom. De esto no se deduce que todas estas conquistas tengan que atribuirse únicamente a Gesen, pero hay que reconocer que tenemos en él a un jeque influyente, digno compadre de Tobías. En medio de estos pueblos árabes y filisteos aparece también Edom, pueblo emparentado con Israel pero además su archirrival histórico que también hace parte de este movimiento que ahora se opone a la influencia imperial de los persas, olvidando su apoyo a la invasión babilónica en 597 .

Es sintomático que el texto simplemente mencione a la profetiza Noadias y a los demás profetas como pertenecientes al grupo de los opositores (Neh 6,14). Aunque es lógico este ocultamiento, se puede inferir que esta profetiza bien podría pertenecer al grupo de mujeres sabias del posexilio y los demás profetas, tendríamos que buscarlos entre algunos de los posexílicos, no precisamente profetas del templo como Ageo, sino aquellos que cuestionan a las élites de Edom e Israel con influencia de corrientes como la de Abdías (Schwantes, 2002, pp. 169-174) o semejantes.

En conclusión, lo que hemos dicho es que existe en la época de Nehemías un gran movimiento 
que se opone a la reconstrucción de Jerusalén, no porque no quiera el renacer de la región sino por la influencia imperialista que esta acción conlleva. Este gran movimiento estaba conformado no solamente por los que habían sobrevivido al destierro babilónico y algunos de los(as) que retornaron del exilio, sino por que prácticamente todos los vecinos históricamente emparentados con Israel y aquellos que ya formaban parte de dicho movimiento, por su permanencia histórica en la región como los habitantes filisteos del litoral. De este gran movimiento haría parte la propuesta de mujeres como Ruth y otras como las mujeres del Cantar de los Cantares que inspiran la literatura sapiencial y literatura afín que se configura en el posexilio. Como parte de esta conclusión caracterizamos los proyectos en contienda en el siguiente cuadro:

\begin{tabular}{|c|c|c|}
\hline Tópicos & Proyecto oficial & Proyecto alternativo \\
\hline Representantes & $\begin{array}{l}\text {-Rey persa } \\
\text { - Nehemías (representante del } \\
\text { Imperio Persa en Palestina) } \\
\text { - Esdras (teólogo palestino } \\
\text { a favor del Imperio Persa) }\end{array}$ & $\begin{array}{c}\text { - Tobías (Gobernador de } \\
\text { Transjordania) }\end{array}$ \\
\hline $\begin{array}{c}\text { Sectores } \\
\text { sociales aliados }\end{array}$ & $\begin{array}{l}\text { Sacerdocio Militares } \\
\text { Trabajadores armados }\end{array}$ & $\begin{array}{c}\text { - Eliasib (sacerdote) } \\
\text { - Noadías (profetiza) } \\
\text { - Profetismo popular } \\
\text { - Sabias y sabios populares (Ruth) }\end{array}$ \\
\hline $\begin{array}{c}\text { Teologías } \\
\text { legitimadoras }\end{array}$ & $\begin{array}{c}\text { - Yavismo "oficial" (Ley = Pentateuco) } \\
\text { - Teología del culto (templo) }\end{array}$ & $\begin{array}{l}\text { Yavismo popular (Dios liberador que } \\
\text { los sacó de Egipto, que se mueve } \\
\text { en medio de las tribus y que no } \\
\text { requiere de templo) }\end{array}$ \\
\hline
\end{tabular}

\section{Develación del proyecto oficial}

Mientras que en el anterior ítem fueron caracterizados los opositores y comparado su proyecto con el que detentaba Nehemías, como representante de los persas, en el presente intentaré mostrar cómo este proyecto opositor logra develar esa estrategia de poder junto a su "fortaleza" religiosa.

Como es apenas lógico, en el texto del libro de Nehemías no describe todos los elementos que conformaba la propuesta del proyec- to opositor y su lectura de esta propuesta es claramente negativa. Sin embargo, sí es posible identificar algunas pistas que nos conducen a la develación del proyecto oficial en cabeza de Nehemías. Lo primero que los redactores finales del texto señalan es que "Sambalat horonita y Tobías el siervo amonita, les disgustó en extremo que viniese alguno para procurar el bien de los hijos de Israel" (Neh 2,10). Apartándonos del sesgo interpretativo al interior de este juicio de valor pudiéramos fijarnos, más bien, en las razones de dicho "disgusto extremo". La expresión en hebreo es h[“är" h,Pl'[r; YEïw: (wayerah 
lahem rahab). Lo que esa expresión significa no es tanto que ellos se hayan disgustado como dicen las traducciones, sino que ellos vieron este asunto como algo extremadamente negativo y la razón que se infiere es que, en esos momentos, Palestina es una región que está intentando salir adelante con sus propios recursos, pero ahora corre serio peligro de perder la autonomía relativa que habían logrado para quedar a expensas de las políticas del rey persa de manera definitiva.

Luego, más adelante, se hace todavía más clara la denuncia de los representantes del proyecto opositor contra Nehemías y su grupo pues son tildados de $\sim$ ylipl'mea] ('melagim), esto es, desgraciados, desdichados, miserables. A su entender, lo que estos judíos estaban haciendo con su pretendida rápida reconstrucción de los escombros, se vendría a tierra con el paso de una zorra (Neh 4,3 RV). Esto era una metáfora para dar a entender que este proyecto, en general, carecía de la suficiente solidez como para perdurar y convertirse en una respuesta de vida que respondiera a las necesidades y requerimientos de la población tanto nativa como de aquellos que estaban regresando de la experiencia del exilio.

Un tercer hecho que devela, de manera explícita, el proyecto de Nehemías se constata por la política milistarista que adopta para responder a las críticas incontestables del proyecto opositor para lo cual primero ora a Dios, que sustenta dicha política (Neh. 4,9). Es así como en las partes bajas donde estaban reconstruyendo, detrás del muro, armó al pueblo con sus armas domésticas (Neh 4,13) y además de la táctica de autodefensa que se impone a los trabajadores (Neh 4,18), militariza la sociedad (Neh 4,21-22) para garantizar que, por las vías de hecho, fuera garantizada el control absoluto de la población y la imposición por la vía armada de la propuesta política foránea.
Una cuarta evidencia develadora del verdadero carácter del proyecto de Nehemías se manifiesta en la denuncia del capítulo 5 , que se convierte en gran clamor del pueblo y de las mujeres contra sus hermanos judíos: habían tenido que pedir prestado grano para comer y vivir; se habían visto obligados a empeñar sus tierras, sus viñas y sus casas para poder comprar grano y así alimentarse; incluso habían tenido que pedir prestado dinero hipotecando sus parcelas, para pagar el tributo del rey; pero la denuncia no para ahí, sino que además manifiestan que sus hijos y sus hijas habían sido empeñados(as) y ahora no tenían cómo pagar el rescate, debido a que las tierras que les habían prometido ya no eran de ellos(as) sino de los detentores del poder imperial (véase también Neh 9,36-37), a través de Nehemías que se presentaba como el gran benefactor, implementando reformas que a la postre no repercutieron en beneficio para la población (Neh 5,6-14).

\section{5. ¿Hay un vínculo entre los opositores a Nehemías y el proyecto de Ruth?}

Hemos dicho que la llegada de Nehemías a Jerusalén se sitúa por el 445 a.C. Esta es la misma época en que se escribiría el libro de Ruth $^{8}$ (Mesters, 1985, p. 85), que registra una respuesta concreta a Esdras y Nehemías, los cuales expulsaron a las mujeres extranjeras basados en el seguimiento al naciente judaísmo (Esd 9,1-12; Neh 8,1-8; 9,2). Todos(as) sabemos que Ruth se presenta como una mujer de ascendencia moabita y mujeres como ella estarían siendo el foco de los ataques y las expulsiones deliberadas de estos dos personajes que, siendo de origen judaíta, representaban los intereses del imperio de los persas. De manera por demás incoherente con ésta política

8 Véase (Lopes, 2005, pp. 69-77). 
basada en el imperio de la ley, Nehemías estaba garantizando la seguridad de los únicos extranjeros (los persas), que tenían licencia para ejercer control sobre una de las regiones más estratégicas de dicho imperio. Esta situación de persecución, de señalamiento y acusaciones contra las mujeres extranjeras, una de las cuales sería el personaje de la historia de Ruth, es muy semejante a la manera como es tildado Tobías y sus amigos, incluidos la profetiza Noadías, los demás profetas, las mujeres del capítulo 5 y el sacerdote Eliasib (Neh 13,4). Esta identidad entre Tobías y Ruth está claramente probada por el origen amonita de Tobías. Ruth la moabita y Tobías el amonita remontan su origen, según la propia Biblia, al grupo abrahámico al cual pertenecía Moab y Amón, hijos de Lot en sus propias hijas (Gn 19, 30-38).

La identidad de propuestas coincide en la importancia de incentivar un modelo que no privilegia ni el templo, ni la corte del rey, ni el sacerdocio oficial con sus rituales que justifican y desconocen deliberadamente la esclavitud y la injusticia. Es sintomático que en el libro de Ruth estas instituciones no tienen lugar en la propuesta social solidaria (Mena López, 1995) y tribal que propone y que no se conforma con ser vinculada de manera secundaria a los esquemas tributarios de la dinastía davídica, propia de los redactores finales del libro (Ruth 4,13-22).

Esta es la misma situación que no puede ser ocultada ni siquiera en el libro de Nehemías, cuyo redactor final es defensor acérrimo de estas instituciones que pretenden ser recuperadas como vigentes para la defensa de una estructura sociopolítica, como la monarquía que había fracasado estruendosamente. Esto es lo que se lee en Nehemías 13,4-9, en donde el sacerdote Eliasib otorga un lugar a Tobías al interior de los atrios del templo en ausencia de Nehemías. Es el intento de convertir el templo en un lugar solidario, quitándole la función de recaudador de tributos para transformarlo en un espacio eje de economía solidaria, al estilo de la propuesta del profeta Malaquías en su redacción más original (Ml 3,10)9 .

Ahora bien, ¿en qué consiste el proyecto alternativo de Ruth?

El proyecto de Ruth está claramente expuesto a lo largo de su libro. Señalamos cuatro elementos fundamentales que forman parte esencial de éste:

1. Retorno a la tierra que había sido dejada por problemas de hambre (Ruth 1,1.622). El retorno a la tierra implicaba que quienes se habían quedado, el remanente pudiera ahora sí disfrutar de la tierra como propia. También los que regresaban del cautiverio lo hacían para recuperar lo que habían perdido y reconstruir sus familias, pero no para trabajar como esclavos al servicio del rey como se describe en Nehemías 5.

2. La recolección tras de los segadores demarca la importancia de hacer valer el derecho de los pobres de la tierra que había quedado establecido en el Deuteronomio (Ruth 2,1-22; Dt 15,7-11).

3. Era fundamental en dicho proyecto cumplir la ley del rescate para garantizar la posesión de la tierra, el futuro de la familia y del propio pueblo (Ruth 4,1-12; Lev 25,1-25).

4. Hacer de la solidaridad y del cumplimiento de las leyes tribales el fundamento cotidiano del pueblo y darle preponderancia al Yavismo popular yendo más allá de las instituciones de la monarquía como el templo, el sacerdocio, los sacrificios que no son mencionados en el li-

9 Véase mi artículo ¿Casa del tesoro o casa de la provisión? Una lectura de Malaquías 3,10. (2005, pp. 40-43). 
bro, o dándoles un uso diferente como en Nehemías 13,4-9, donde Eliasib había otorgado a Tobías el templo para actividades diferentes al de los tributos, ofrendas y sacrificios.

5. La gente extranjera, pero que se integraba al proyecto de Israel debían ser considerados parte del pueblo. Las mujeres extranjeras, como Ruth, que quisieron regresar para trabajar por el proyecto del nuevo Israel, debían ser rescatadas e integradas a la familia del pueblo de Dios. Esto también debía valer para hombres como Tobías y sus seguidores (Is $56,3.6-7)^{10}$.

En conclusión, se demuestra el vínculo entre quienes se oponen al proyecto de Esdras y Nehemías y la propuesta de Ruth, no solamente por la vía de la identidad y la ascendencia de los personajes, sino por la vía del contenido de la propuesta: ambos(as) resisten al imperio de turno y para ambos(as), el templo debería tener una destinación diferente que los rituales y el recaudo de tributos y estar más al servicio de las causas de la retribalización y la solidaridad con los(as) excluidos(as) y pobres de la tierra. Hay, sin embargo, en Tobías y Ruth dos maneras diferentes de enfrentar la propuesta imperial: mientras que Tobías confronta, en Ruth se plantea una propuesta concreta de sociedad. Probablemente los dos tipos de acción son complementarios y necesarios a la hora de echar a andar una propuesta articulada de transformación al interior de una sociedad determinada.

\section{Su conflicto, nuestro conflicto}

No siempre es posible relacionar los conflictos que aparecen en la Biblia con nuestros propios conflictos. Esa sería en parte una de las tareas de la hermenéutica bíblica. Si ya la propia hermenéutica contextual ofrece una gran dificultad al tratar de colocar los textos en sus lugares sociales e históricos, cuánto más si pretendemos que la Biblia ilumine las situaciones conflictivas propias del intérprete actual. Esa ha sido una dificultad de la lectura popular y comunitaria de la Biblia, porque si en muchas ocasiones se hace difícil la interpretación de la realidad propia, cuánto más las realidades representadas en los textos bíblicos. A pesar de la importancia de reconocer esta dificultad, sigue siendo fundamental que no hagamos una lectura bíblica que caiga en el vacío y que no responda a las emergencias propias de nuestra fe y de las problemáticas que encarna nuestro pueblo del cual todos(s) formamos parte. En el contexto de los esfuerzos de la llamada hermenéutica de la liberación se afirma que: "se trata de una hermenéutica que se sitúa coherentemente en el ritmo de la transformación social, aunque no se reduzca a ella. No es propiamente un nuevo método exegético, pero sí una nueva forma de comprensión del texto a partir de una fe vivida en un contexto de liberación" (Velez, 1988, p. 8). Si esta es nuestra opción de lectura, tendremos que leer la Biblia siempre en la óptica de la marginalidad y desde lo desechado y vituperado, tanto en la Biblia como en nuestro contexto social.

En la óptica de lo anteriormente dicho, la pregunta a propósito del presente artículo es hasta qué punto la problemática generada por el proyecto de restauración de Esdras y Nehemías que generó todo un movimiento de emancipación desde quienes hemos denominado "artífices opositores", puede contribuir a sugerir salidas a las problemáticas propias del conflicto colombiano en nuestros días. Pudiéramos partir de la identificación de algunas categorías comunes entre el conflicto de Tobías y su grupo frente a Nehemías y los

10 Para ampliar esta información sobre el proyecto de Ruth, véase (Mesters, 1986, p. 67). 
persas, y los alzados en armas y el gobierno colombiano. Me parece que este ejercicio de encontrar categorías comunes entre los conflictos que presentan los textos bíblicos y nuestros propios conflictos no está claramente expresado en la llamada hermenéutica de la liberación, ni en la lectura popular y comunitaria de la Biblia.

¿Cuáles serían entonces estas categorías de análisis que pueden resultar comunes? Guardando las proporciones, podemos hablar de unas estructuras establecidas tanto en la época de Nehemías como en nuestra sociedad colombiana que, desde la óptica de quienes las detentan, necesitan ser defendidas, para lo cual se hace necesario la inversión de la mayor cantidad del presupuesto disponible sin importar que repercuta en el sacrificio socio-económico de la población. Otra de las categoría que pueden caracterizar un análisis hermenéutico con elementos comunes es el uso y comercialización de armas a favor de ejércitos y grupos de autodefensa (Neh 4,17-18), que pretenden defender las estructuras establecidas al servicio de intereses, no solamente nacionales sino de grupos económicos extranjeros que se valen de la población nativa para hacer crecer sus negocios. Junto a estos elementos bélicos que arman la población contra sus propios hermanos y hermanas, subyace una política de relaciones internacionales que se implanta a nombre de la seguridad nacional y del grupo en el poder, que tiende a favorecer los intereses económicos y políticos de este grupo que detenta el poder y que se especializa, por intereses propios, en la defensa de los intereses de una potencia o varias potencias extranjeras, a nombre de la prosperidad del país o de la patria.

Esta seguridad nacional, bien controlada por el grupo en el poder, es la que garantiza, entonces, la celebración de acuerdos económicos para favorecer la reconstrucción de infraestructura y supuesto intercambio comercial ventajoso, a cambio de apoyo político y aumento de impuestos a la población, lo cual incrementará el desequilibrio cada vez más inequitativo, haciendo crecer la brecha de dependencia a favor de la potencia que paulatinamente aumenta su presencia militar y su influencia cultural avasallante.

Estos elementos profundamente arraigados en la conciencia de la población van generando paulatinamente el crecimiento de la conciencia de un grupo, de todas maneras minoritario y que, a pesar de sostenerse en la resistencia, no llega a contar con recursos necesarios para revertir a su favor y a favor de la población "alienada", la situación que cada vez se endurece más y se hace más infranqueable, aumentando sus niveles de violencia y represión a nombre de los intereses nacionales y de los grupos de poder establecidos. Esta situación de endurecimiento de la represión oficial obliga al grupo de la resistencia a valerse de mecanismos poco populares, a cometer errores estratégicos y/o a girar en torno a sostener los niveles de resistencia. Se puede convertir en un círculo vicioso que transforma la lucha en una simple posibilidad de subsistencia, incapaz de trascender hacia el establecimiento de la sociedad antaño soñada y que va perdiendo espacios de credibilidad y estancamiento en el apoyo de las masas, captadas cada vez más por los "encantos" y "ofertas" del establecimiento oficial.

Este intento de prueba de categorías comunes como criterio de análisis hermenéutico bien puede servir para cualificar mejor y facilitar los esfuerzos de la lectura popular y comunitaria de la Biblia por hacer eficaz la aproximación al texto bíblico, de tal manera que se haga todavía más contundente la interpretación y genere todavía mayor impacto en la posibilidad de deconstruir las crecientes relaciones de injusticia social y reconstruir los tejidos a partir del fortalecimiento de las relaciones entre el mayor número de fuerzas positivas posibles, comprometidas por encarnar de manera más coherente el evangelio de nuestro maestro Jesús de Nazareth. 
¿Qué salidas pacíficas pueden ser propuestas para el conflicto colombiano a partir de la lectura de Nehemías desde los artífices opositores?

1. Encontrar estrategias para el desarme de toda la población, incluyendo grupos alzados en armas; establecer fuerzas de paz en las fronteras y crear policía cívica al estilo de Costa Rica.

2. Generar propuestas concretas para integrar en el gobierno a las fuerzas opositoras y proyectos gubernamentales de empresa y empleo para las comunidades marginadas.

3. Destinar la mayor parte de la ayuda internacional vía gobierno para impulsar el movimiento social (Neh. 5,10-12).

4. Generar una política efectiva de retorno de la población desplazada a su tierra y garantizar apoyo económico para que puedan hacerla productiva.

5. Invitar a las iglesias a convertir, cada vez más, sus templos en centros de ayuda humanitaria y espacios para que la vivencia de la espiritualidad contribuya a la concientización, a la actitud crítica, vía propuestas de paz y justicia social (Neh. 13,4-5).

\section{Conclusiones}

1. Nuestro ejercicio comenzó por presentar una interpretación de cierto aspecto de la estructura literaria del libro de Nehemías, enfocándola desde la óptica de los artífices opositores frente a la propuesta central del libro que favorece la incidencia de la propuesta del imperio persa en Palestina en la época del retorno de los judíos a su tierra, después del destierro ejercido por los babilonios.
2. El análisis de esta estructura nos llevó a identificar aquellos textos que registran el grupo de los artífices opositores y a otorgarles un reconocimiento crucial en la dialéctica interna de la obra de Nehemías. Fueron valorados como un movimiento que contribuye a generar conciencia en las clases populares en donde también participan profetas, profetizas, sacerdotes, las mujeres y un sector importante del pueblo en general.

3. El grupo de los artífices opositores a la propuesta de reconstrucción de Jerusalén y de la nueva provincia persa fueron caracterizados como personas de gran influencia en la región y que tenían como propósito impulsar una reforma de nacionalismo autónomo que no contara con el auspicio político de los persas.

4. La propuesta liderada por Tobías y su grupo fue identificada como una propuesta que guarda especial identidad con el auge que tuvo en el posexilio una corriente de sabios y sabias, de la cual participaban mujeres como las que presenta la novela de Ruth y las mujeres del Cantar de los Cantares y el libro de los Proverbios. En ese grupo influyente de sabios y sabias también confluía el profetismo popular, al cual pertenecía profetisas como Noadías.

5. Las categorías hermenéuticas, propuestas para el cualificar el análisis de la realidad, a propósito de los contenidos estructurales del libro de Nehemías, establecen una relación que puede ser creativa y determinante para cualificar el trabajo de la lectura popular y comunitaria de la Biblia. Estas categorías son: (A). Una estructura política establecida que desde la óptica de quienes la defienden requiere ser defendida. (B) Resistencia ejercida por un grupo minoritario, pero con suficiente 
influencia y propuesta de alternativa sociopolítica. (C) Incremento de la autodefensa por parte del grupo que detenta el poder para garantizar ciertos niveles de seguridad. (D) Celebración de acuerdos económicos para favorecer reconstrucción de infraestructura y supuesto intercambio comercial ventajoso a cambio de apoyo político y aumento de impuestos a la población. (E) Aumento de la presencia militar e influencia cultural avasallante. (F)
Pérdida del horizonte ideológico del grupo de resistencia y decaimiento de la propuesta alternativa que repercute en repunte de la política oficial y aumento de la represión y la violencia.

6. El estudio de la palabra de Dios, vía lectura popular y comunitaria de la Biblia, debe propender cada vez hacia propuestas para la búsqueda de salidas pacíficas al conflicto colombiano. 


\section{Referencias bibliográficas}

Arias Ardila, E. (2005). ¿Casa del tesoro o casa de la provisión? Una lectura de Malaquías 3,10. Revista de Interpretación Bíblica Latinoamericana, 50(1), pp. 40-43.

. (Junio, 2011). Contexto literario de Nehemías. Trabajo inédito presentado en memorias curso afro, Medellín.

Cañaveral, A. (2012). Andar en el Encanto de la Palabra. Diálogo de saberes en Artífices, entradas llaves y claves. Bogotá: Cedebi.

Croatto, J. S. (1989). Isaías 1-39. Cometario bíblico ecuménico AT. Buenos Aires: La Aurora. . (1990). La deuda en la reforma social de Nehemías. (Un estudio de Nehemías 5:1-19). Revista de Interpretación Bíblica Latinoamericana, 5-6, pp. 27-37.

Días Mariano, L. (2004). Los/as extranjeros/as dicen: "Yahweh no nos excluirá de su pueblo!" Manifiestos contra el imperialismo en la teología de reconstrucción. Revista de Interpretación Bíblica Latinoamericana, 48, pp. 40-50.

Gallazzi, S. (1998). Aspectos de la economía del segundo templo. No abandonaremos más la casa de nuestro Dios (Ne 10,40). Revista de Interpretación Bíblica Latinoamericana, 30, pp. 55-72.

Gottwald, N. (1992). La Biblia Hebrea. Una Introducción socioliteraria. Barranquilla: STP.
Kilpp, N. (2005). Esdras y Nehemías. Revista de Interpretación Bíblica Latinoamericana, 52, pp. 131-142.

Lockward, A. (2003). Nuevo Diccionario de la Biblia. Miami: Unilit.

Lopes, M. (2005). El libro de Rut. Revista de interpretación Bíblica Latinoamericana, 52, pp. 69-77.

Mesters, C. (1986). Rute. Comentário Bíblico. Petrópolis-Sao Leopoldo: Vozes-Sinodal. . (1985). Rute-uma história da Biblia-pao, familia, terra! Quem vai por aí nao erra! Sao Paulo: Paulinas.

Mena López, M. (1995). A Forca da solidariedade. O libro de Rute numa perspectiva negra y feminista. Sao Paulo: Koinonia.

Michaud, R. (1988). Qobelet y el helenismo. Navarra: Verbo Divino.

(1995). La literatura sapiencial. Proverbios y Job. Navarra: Verbo Divino.

Schwantes, M. (2002). Historia de los orígenes de Israel. Quito: Verbo Divino.

. (1995). La literatura sapiencial. Proverbios y Job. Navarra: Verbo Divino.

Vélez, N. (1988). La lectura Bíblica en las CEB'S. Revista de Interpretación Bíblica Latinoamericana, 1,8 . 